\title{
Geographical thoughts on the relationship between 'Beautiful China' and land spatial planning
}

\author{
CHEN Mingxing ${ }^{1,2}$, LIANG Longwu ${ }^{1,2}$, WANG Zhenbo ${ }^{1,2}$, ZHANG Wenzhong ${ }^{1,2}$, \\ YU Jianhui ${ }^{1,2}$, LIANG Yi ${ }^{3}$ \\ 1. Key Laboratory of Regional Sustainable Development Modeling, Institute of Geographic Sciences and Nat- \\ ural Resources Research, CAS, Beijing 100101, China; \\ 2. College of Resource and Environment, University of Chinese Academy of Sciences, Beijing 100049, China; \\ 3. Center of Land Consolidation, Ministry of Natural Resources, Beijing 100035, China
}

\begin{abstract}
The concept of 'Beautiful China' is a new goal of ecological construction in the new era of socialism and aims to meet the needs of people as they strive for a better life. National land spatial planning is one major component of the Chinese state's overall planning for various spatial types. The concept of 'Beautiful China' is thus a leading goal of Chinese development in the second centenary. The background of this concept aims for 'ecological beauty' as well as the combined beauty of 'economy-politics-culture-society-ecology.' The construction of 'Beautiful China' therefore necessitates a differentiated evaluation index system that is built on the basis of local conditions. This concept is intimately related to land spatial planning and the idea of Beautiful China guides an important direction for this planning which itself provides an important mechanism and spatial guarantee for construction. The establishment of land spatial planning nevertheless needs to strengthen further discussion of the regional system of human-land relationship, point axis system, main functional division, sustainable development, resources and environmental carrying capacity as well as new urbanization, and the rural multi-system. The aim of this paper is to summarize current thinking in land spatial planning, scientifically analyze the natural geographical conditions, the socioeconomic development, the interrelationship of the land space, plan the goal, vision and path of land space, encourage the public to participate in and carry out dynamic evaluation, build an intelligent system platform for land and spatial planning to realize the goal of 'Beautiful China' from a geographical perspective. And they can also present key ideas relating to the compilation and implementation of land spatial planning.
\end{abstract}

Keywords: Beautiful China; land spatial planning; ecological civilization; modernization of space governance; geographical science

Received: 2020-01-31 Accepted: 2020-03-10

Foundation: National Natural Science Foundation of China, No.41822104, No.41671125; The Strategic Priority Research Program of the Chinese Academy of Sciences, No.XDA23100301

Author: Chen Mingxing (1982-), PhD and Professor, specialized in urbanization and regional sustainable development. E-mail: chenmx@igsnrr.ac.cn 


\section{Introduction}

The concept of 'Beautiful China' is a crucial strategic idea and task proposed in the Report of the 18th National Congress of the CPC in 2012. It is also a new way to achieve the Two Centenary Goals and the Chinese dream of great national rejuvenation. This concept also aims to realize the comprehensive and effective development of economy, politics, culture, society, and ecology. In May 2018, General Secretary Xi Jinping clearly outlined the timetable and road map for building a Beautiful China at the National Conference on Environment Protection. He outlined that 'to ensure that by 2035 , the ecological environment quality will be fundamentally improved and the goal of Beautiful China will be basically achieved and that by the middle of the 21 st century, humans and nature will live in harmony, the modernization of national governance systems and capacity in the field of ecological environment will be realized in an all-round way for a Beautiful China' (XNA, 2018). Indeed, since the 'Beautiful China' concept was proposed, the academic community has pursued research themes from different perspectives, emphasizing theoretical connotations (Li, 2013; Wan et al., 2013), assessment plans (Fang et al., 2019), evaluation criteria systems (Gao et al., 2019a), summaries of experiences (Gao et al., 2019b), land spatial planning (Huang et al., 2018), and Chinese tourism development (Shi et al., 2018).

The May 2019 Official Opinions on the Establishment and Supervision of the Implementation of Spatial Planning System of National Territory noted that China would develop an overall plan for the framework of territorial space development and protection in the new era as well as a scientific layout for production, living, and ecological space. These developments are consistent with the overall goal of building 'Beautiful China.' In this context, a national territory development plan provides an overall scheme for coordinating regional resource spatial allocation, development management, and layout optimization and is therefore of great significance in promoting regional coordinated development (Fan, 2004; Healey, 1998). As global attention has increasingly been focused on the rational development and utilization of territorial space, land spatial planning has become an important component of international and national governance systems. Indeed, in 1999, the European Union (EU) adopted a 'European Spatial Development Vision (ESDP)' space plan and developed common goals and concepts regarding future regional development. The EU also undertook a comprehensive analysis of the framework and connotations of spatial planning in the 21st century (Liu et al., 2008). Similarly, in 2006, the United States government formulated the 'America 2050' land spatial planning for future national land development as a way of mitigating problems of rapid population growth, infrastructural demands, economic development, and environmental pressures in the 21st century (Liu et al., 2013). China has also successively developed a series of important spatially-related plans, including for development priority zones, land use, urban and rural, and new urbanization (Chen et al., 2016a). In the context of Multiple Planning Integration Reform in the new era, land spatial planning has also ushered in a period of major reform and development opportunities. It is imperative to do a good job in terms of top-level land spatial planning design to give full play to the basic roles of land spatial planning in the national planning system and to provide spatial guarantees for the implementation of national development planning. This enables development of a spatial blueprint of national sustainable development. The field of geography, in particular, has produced a large volume of basic research assessing the theory and 
practice of land spatial planning (Chen et al., 2016b).

The construction and land spatial planning involved with the 'Beautiful China' concept have become two important themes closely related to geographic development. These themes provide great opportunities for the development of geography, especially human and economic areas. Construction and land spatial planning underlying 'Beautiful China' are currently newly emerging; this means that the academic community has not coalesced around our unified understanding of 'Beautiful China' and land spatial planning. There are currently few documents available to analyze the organic relationship between 'Beautiful China' and land spatial planning. This paper therefore proposes a new cognitive concept of the goal of 'Beautiful China' and land spatial planning and provides a theoretical basis for land spatial planning that can be strengthened in future work. This paper presents a methodological framework for land spatial planning and aims to provide theoretical and methodological support in this area as well as new ideas aiding the construction of 'Beautiful China.'

\section{The concept of 'Beautiful China' is the leading national second centen- ary development goal}

\subsection{The Two Centenary Goals and construction of 'Beautiful China'}

Subsequent to founding of the People's Republic of China in 1949, remarkable development achievements have been made and the country has entered into a new era of socialism with specific national characteristics. In order to realize this Chinese Dream, the government put forward "The Two Centenary Goals" which aim to complete building a moderately prosperous society by the time the Communist Party of China celebrates its centenary in 2021 . The goal is therefore to also turn China into a modern socialist country that is prosperous, strong, democratic, culturally advanced, harmonious, and beautiful by the time the People's Republic of China celebrates its centenary in 2049. In light of developmental changes, Chinese national strategy made a number of key changes in terms of realistic needs, developmental stage and goal as well as ideas and spatial governance (Table 1). In the context of a new era of socialism with Chinese characteristics, construction of 'Beautiful China' enables

Table 1 New goals and changes with socialist characteristics

\begin{tabular}{|c|c|c|c|}
\hline \multirow{2}{*}{ Category } & \multirow{2}{*}{ 1949-early 21 st century } & \multicolumn{2}{|c|}{ The new era with socialist characteristics } \\
\hline & & New goals & New changes \\
\hline $\begin{array}{l}\text { Facing different } \\
\text { needs }\end{array}$ & $\begin{array}{l}\text { Mainly solve problems to do } \\
\text { with food, clothing, and a } \\
\text { prosperous life }\end{array}$ & The desire for a better life & Eat well and enjoy a high-quality life \\
\hline $\begin{array}{l}\text { Developmental } \\
\text { stage succession }\end{array}$ & $\begin{array}{l}\text { Emphasis on industrial civi- } \\
\text { lization }\end{array}$ & $\begin{array}{l}\text { Realizing ecological civili- } \\
\text { zation }\end{array}$ & $\begin{array}{l}\text { Respecting nature and that clear waters } \\
\text { and lush mountains are invaluable assets. } \\
\text { Adhering to green development }\end{array}$ \\
\hline $\begin{array}{l}\text { Upgrading of } \\
\text { development } \\
\text { goals }\end{array}$ & $\begin{array}{l}\text { Focus on economic growth } \\
\text { and providing a richer mate- } \\
\text { rial basis }\end{array}$ & $\begin{array}{l}\text { Constructing 'Beautiful } \\
\text { China' }\end{array}$ & $\begin{array}{l}\text { Multi-dimensional development and ad- } \\
\text { vocating people-oriented economic, social } \\
\text { and ecological goals }\end{array}$ \\
\hline $\begin{array}{l}\text { Changing de- } \\
\text { velopmental } \\
\text { thought }\end{array}$ & $\begin{array}{l}\text { High-speed economic growth } \\
\text { in all regions }\end{array}$ & $\begin{array}{l}\text { Different regional functions } \\
\text { in regions }\end{array}$ & $\begin{array}{l}\text { Adapting to local conditions and seeking } \\
\text { optimized, key, restricted, and prohibited } \\
\text { development }\end{array}$ \\
\hline $\begin{array}{l}\text { Changing spatial } \\
\text { governance }\end{array}$ & $\begin{array}{l}\text { Strip and multi-head man- } \\
\text { agement of land and space }\end{array}$ & $\begin{array}{l}\text { Overall planning and man- } \\
\text { agement of land and space }\end{array}$ & $\begin{array}{l}\text { Overall planning of 'production-living- } \\
\text { ecological' spaces to realize the moderni- } \\
\text { zation of space management }\end{array}$ \\
\hline
\end{tabular}


a new goal and developmental vision for national second centenary development. This scheme also presents the most important direction for future land spatial planning.

\subsection{The concept of 'Beautiful China' represents not only ecological beauty but also a comprehensive connotation of 'great beauty'}

Subsequent to the proposal of the 'Beautiful China' concept, all levels of national government have successively strengthened the work of ecological environmental protection and undertaken environmental pollution prevention and control, ecological and urban restoration, and human settlement improvements. These innovations have created a construction mode of 'Beautiful China' encompassing local characteristics such as 'beautiful Zhejiang' (Fu et al., 2018), 'beautiful Fujian' (Fu et al., 2019), 'beautiful Jiangxi' (Hu et al., 2018) and 'beautiful Yunnan' (Zhang, 2018). Nevertheless, as part of the process of exploring 'Beautiful China' construction, a number of misunderstandings have developed around the idea that the construction of Beautiful China only needs to do well in ecological construction. This is incorrect: the construction of Beautiful China is supposed to be a collective concept which aims to create a resource-saving and environment-friendly society as well as a beautiful home comprising 'intensive and efficient production space, livable living space and beautiful ecological space'. The idea is to also comprehensively promote the overall development of China's five-pronged strategy of coordinated process in economy, politics, culture, society

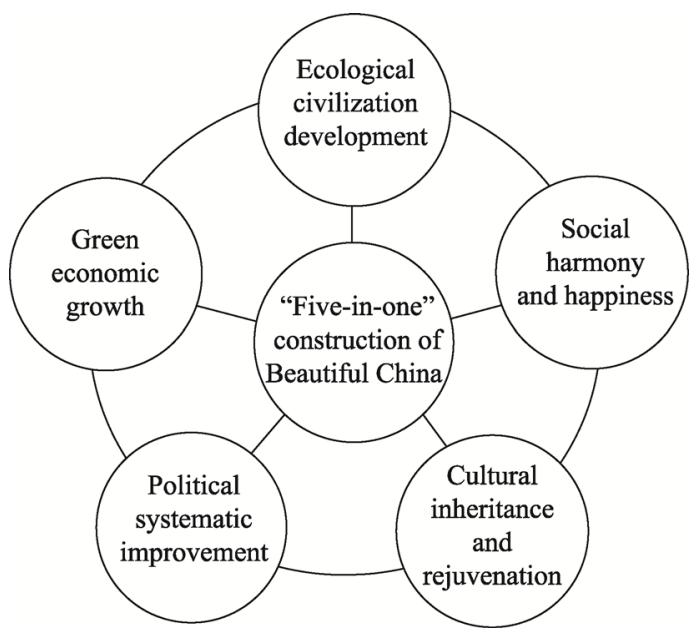

Figure 1 The 'five-in-one' construction goal of 'Beautiful China' and ecology. Economic construction is fundamental, political development is guaranteed, cultural construction is spiritual, social construction is required and the ecological civilization construction is the foundation (Wang et al., 2012). This means that China can only achieve the overall construction goal of Beautiful China by achieving green economic growth, political systematic improvements, cultural inheritance and rejuvenation, social harmony and happiness, as well as the development of ecological civilization. These are the mechanisms by which the Chinese nation can realize great rejuvenation and sustainable development(Figure 1).

\subsection{In order to build 'Beautiful China', it is necessary to create an index evaluation system encompassing different scales and regions}

The rapid development of industrialization and urbanization within China has also led to a number of 'urban diseases' such as ecological damage (Wang et al., 2018), heavy smog (Fang et al., 2016), and comprehensive environmental pollution (Wang et al., 2019). These factors have hindered the sustainable development of cities even though urban expansion has been effectively promoted while the economic level and living conditions of urban residents have been enhanced (Chen et al., 2015). The idea that local governments regard gross do- 
mestic product as the only valuable pursuit means that urban spatial planning has only focused on economic development rather than city quality. This also means that the phenomenon of 'thousands of cities on one look' (Fan et al., 2016) is prevalent in eastern, central, and western regions of China where local culture remains insufficient and urban residents have a depleted sense of belonging and well-being. The construction of 'Beautiful China' is therefore targeted to break through the existing 'aesthetic mediocrity' dilemma faced by urban construction and to improve the urban landscape by highlighting regional characteristic cultures. This means that during the process of building 'Beautiful China,' eastern, central, and western regions must also adapt their implementation measures to local conditions, place full emphasis on their regional advantages, and focus on creating local characteristics. Differentiation in objectives and establishment priorities at national, provincial, municipal, county, and township levels land spatial planning should be seen. National land spatial planning focuses on top-level design and therefore emphasizes development strategy, orientation and general thought, as well as organizational and management tasks such as planning preparation procedures, approval, and assessment. In light of this, emphasis at city, county, and township levels is placed on specific implementation measures as well as on promoting the rational and orderly utilization of every piece of land and space. Provincial units are therefore responsible for intermediate connections, which means they must pay attention not only to strategic direction, but also develop practical guidelines that are significant for the next level of land spatial planning. This enables these regions to perform well in the top-level design and layered implementation of the 'Beautiful China' concept (Figure 2). As part of the process of evaluating the effects of 'Beautiful China' construction, it is therefore necessary to develop a multi-dimensional, multi-level, multi-objective, and multi-standard evaluation index system that encapsulates different spatial scales and regional differences.

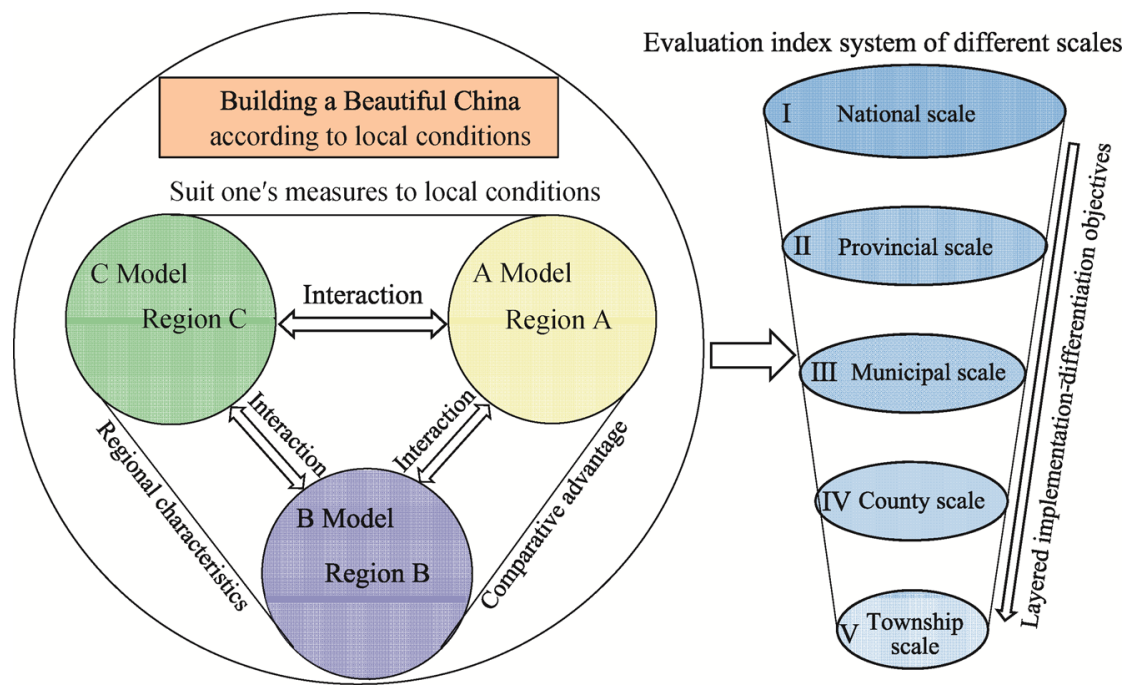

Figure 2 Construction outline to 'adapt measures to local conditions,' part of the 'Beautiful China' concept

As part of the process of building 'Beautiful China' across different spatial scales, authorities at the state level should strengthen top-level design and organizational leadership 
and issue instructive strategic planning and phased policy documents to their subordinates. Similarly, at the provincial level, it is necessary to formulate an implementation outline for the construction of 'Beautiful China' in order to take the lead in the development of this concept. At the city level, specific action plans should be formulated that encompass the overall layout of multi-element beautiful construction, while at the county level, it is necessary to actively implement the construction plan and create model areas within the 'Beautiful China' concept. Finally, it is necessary to comprehensively promote 'Beautiful China' construction at the township level in order to ensure that these areas become the birthplace for this dream. Significant differences in the natural background of different regions must also be kept in mind during the process of building 'Beautiful China', and the 'Beautiful China' construction is supposed to have different focuses.

\section{Land spatial planning reform: Relationship with the 'Beautiful China' concept}

\subsection{Changing from multi-management to a blueprint to realize multi-disciplinary land and spatial planning}

The purpose of land spatial planning is to coordinate the sustainable development of regional space as well as to prevent and control imbalances and the disordered development spatial structures (Yu et al., 2016). Thus, subsequent to 1978 national reform and opening-up, the Chinese government has paid more attention to land spatial planning. National ministries and commissions, including the National Development and Reform Commission, the Ministry of Land and Resources, the Ministry of Housing and Urban Rural Development, the Ministry of Ecological Environment, and the State Oceanic Administration, have presided over the preparation of different forms and levels of planning. These have comprised major functional area, land use, land spatial structure, urban and rural, ecological environmental protection, and marine functional area planning strategies and have all strongly supported the sustained and rapid development of the economy and society even though a series of urgent problems have demanded prompt solutions. The Fifth Plenary Session of the 18th Central Committee of the Communist Party of China therefore proposed to coordinate land spatial planning on the basis of various functional areas and to transition from multi-management to 'one blueprint.' This Plenary Session also promoted 'multi-compliance and integration' in order to more effectively realize innovative development of multi-disciplinary land spatial planning (Figure 3). In the past, land spatial planning faced a range of dilemmas including multi-management, multi-research, and multi-planning; these days, however, contradictions and constraints among departments are expected to have fundamentally improved. Thus, via top-level design of institutional adjustments, the Ministry of Natural Resources has realized the unified deployment and management of land and space. In order to achieve the general goal of realizing the 'Beautiful China' concept in the modern era, land spatial planning also necessitates the multi-disciplinary integration of geography, planning, resources, and environmental science. Innovation in such areas such as systematic mechanisms, theoretical systems, organization and management, applied technology, mode route, and ideology will also be necessary. 


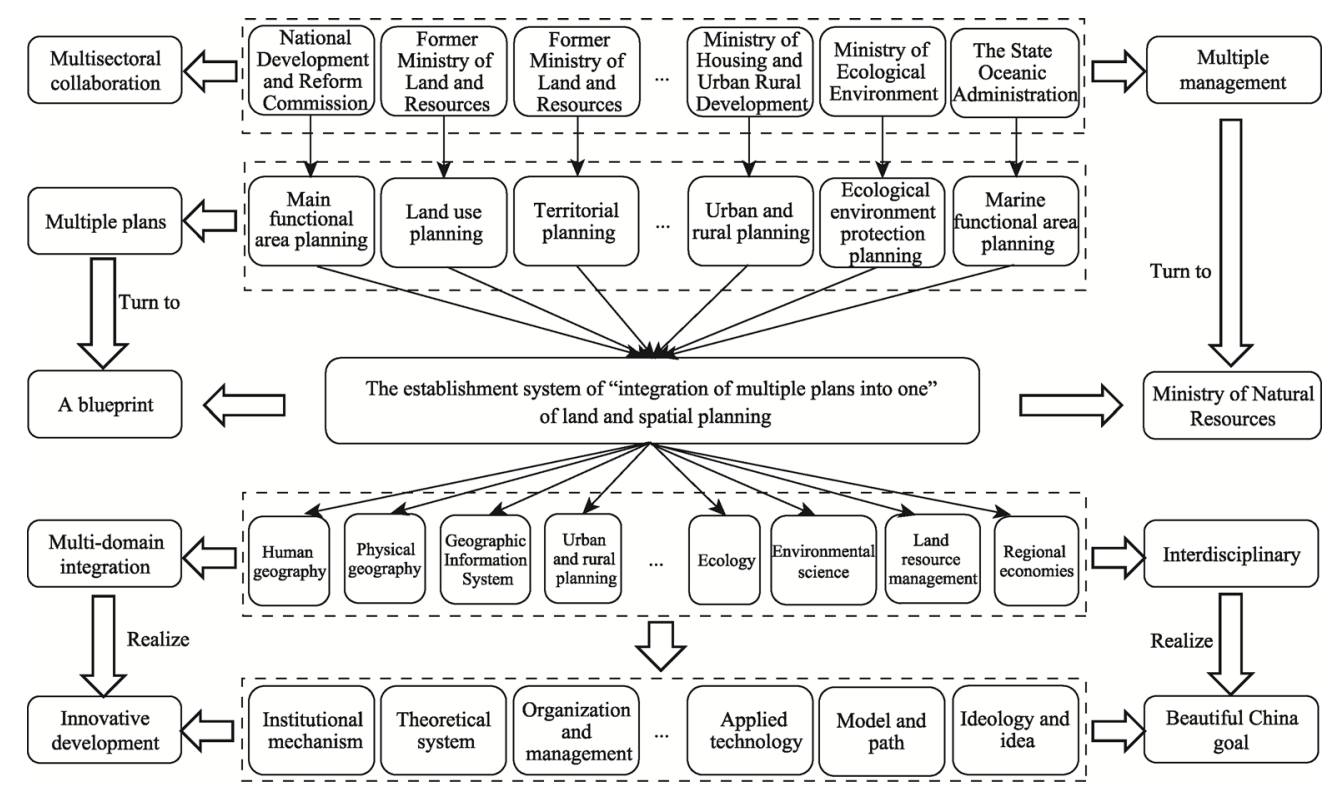

Figure 3 Compilation system of land and spatial 'multi-compliance and integration' planning within the 'Beautiful China' concept

\subsection{Land spatial planning is one important way to realize the modernization of space governance under the guidance of the 'Beautiful China' goal}

The 'Beautiful China' concept encapsulates the new goals and development vision of Chinese modernization in the new era. This concept therefore guides important land spatial planning decisions nationally in order to meet people's desires for a better life. Thus, land spatial planning is one important way in which 'Beautiful China' goals will be met, it provides a significant mechanism and space guarantee for 'Beautiful China' construction. One of the most important ways to measure Chinese capacity and governance level is to scientifically formulate land spatial planning and promote 'Beautiful China' construction (Fan et al., 2017). In the past when many plans were put into action that encompassed parallel multi-management processes, complicated approval procedures and planning features contradicted each other and led to significantly increased planning and construction costs. This confusion influenced the modernization of Chinese systems and overall capacity for governance (Liu et al., 2016), especially spatial governance modernization. Thus, major reform measures of land spatial planning conform to the original intention of the 'unified implementation of land and space use control' (Lin et al., 2018). Geographical science has contributed the long-term scientific foundation to 'Beautiful China' construction and land spatial planning. Major national strategies also provide unprecedented opportunities for the development of geographical science disciplines (Figure 4).

\subsection{Transition from the extrapolation of historical data models to the prediction of planning objectives based on the key goals of 'Beautiful China' and the historical data analysis}

The concept of land space is a massive and dynamic human-land relationship system that 


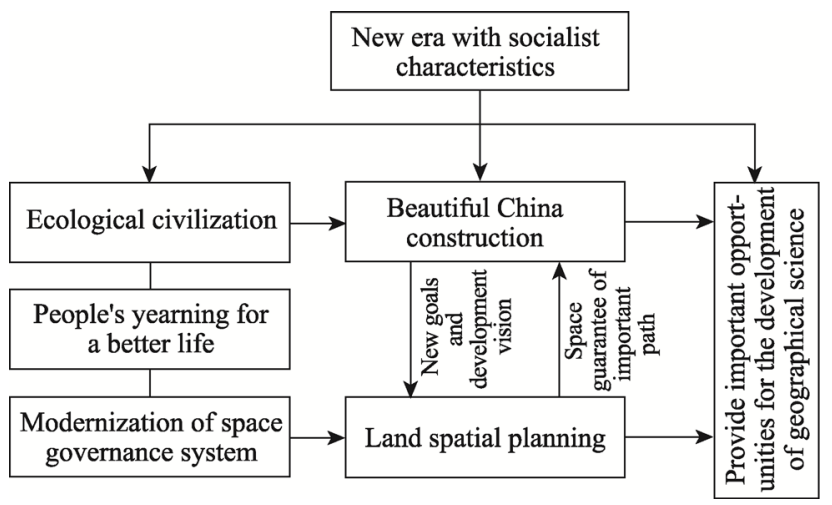

Figure 4 The relationship between the 'Beautiful China' concept and land spatial planning encompasses interactions between human factors such as population, society, economy, innovation, globalization, and infrastructure with natural factors such as the ecological environment, water and land resources, energy, the environment, and climate (Zhang and Fang, 2016). Based on historical process evolution data and on the premise of accurately understanding the dynamic complex giant system of land space and its internal multiple elements positive and negative feedback mechanism and dynamic evolution law, land spatial planning is to build multi-element, linear, non-linear, dynamic and discrete scenario simulation and trend prediction models, so as to scientifically predict and reasonably plan the future land space development and utilization (Zhang and Chen, 2016). Land spatial planning developmental goal prediction has therefore transitioned over time from the extrapolation of historical processes to future predictions by combining the key goals of the 'Beautiful China' concept with historical data analysis. This has enabled the coordinated development and utilization of land and space and has also promoted the orderly development of economy and society (Meng et al., 2015). Thus, via the key goals of 'Beautiful China' construction and constraints on land spatial planning such as 'adhering to people-oriented development to achieve high-quality development and high-quality life and building a beautiful home', the scientific layout of 'production-living-ecological' spaces, and 'comprehensively improve the modernization level of land space governance system and governance capacity, and moderately form an intensive and efficient production space, a livable and appropriate living space, a beautiful and safe ecological space and harmonious, competitive and sustainable land space pattern by 2035', China can continue to strengthen natural environmental protection, which will enable the development of a new pattern of land spatial development and protection in the new era that is based on 'goal orientation and process constraint.'

\section{The geographical theory and cognitive basis underlying the 'Beautiful China' concept and the land spatial planning}

\subsection{Regional human-land relationship}

The material basis that underlies land spatial planning is the effective coordination of a harmonious, pluralistic, and orderly human-land relationship. This means that entire components of the human-land relationship must be considered for overall planning and management. The Academician Wu Chuanjun (1979) proposed a regional system theory for the human-land relationship and pointed out that this system actually comprises a dynamic and complex giant that consists of the interactions between the geographical environment and human activities ( $\mathrm{Wu}, 2008)$. Because of excessive human activities, the elements of society and the natural ecological environment are now characterized by unbalanced and uncoordi- 
nated developmental trends which have led to ecological environmental damage and urban problems. The regional system theory of human-land relationships therefore aims to elaborate the interaction modes of all elements and promote coordinated development and comprehensive optimization.

\subsection{The point-axes system}

Point-axis system theory was first proposed by Mr. Lu Dadao, a famous Chinese human geographer, at the 'National Symposium on Economic Geography and Land Planning' that was held in 1984 in Urumqi. Subsequently, based on long-term research and in-depth practical experience of Chinese macro-regional development, Academician Lu further elaborated on 'the formation process of the point-axis spatial structure,' 'the structure and type of the development axis,' 'the gradual diffusion of the point-axis,' and 'the point-axis-aggregation area.' He published a series of research articles and developed a complete theoretical understanding of the point-axis system (Lu, 1987, 1988). Point-axis system theory has been widely utilized subsequently across many disciplines and research fields (Fan et al., 2015; Fang et al., 2015a; Li et al., 2001; Zhang et al., 2010) and is now recognized as comprising the two most effective applied achievements in Chinese human geography (Lu et al., 2002). This theoretical structure has also been applied in the Outline of National Land Master Planning and is the scientific basis for the ' $\mathrm{T}$ ' structure implemented in Chinese land development.

\subsection{Major functional area theory}

The theory of a major functional area is one of the most important guiding ideologies underpinning Chinese land spatial planning. Thus, on the basis of the comprehensive carrying capacity of resources and the environment, the density of land spatial development, and the potential for future planning and utilization in different regions, geographers recognize four types of potential land development, i.e., optimized development, key development, restricted development, and forbidden development areas (Fan, 2007). The division of these major functional areas adheres to the 'people-oriented' principle, with emphasis on the harmonious coexistence and coordinated development of human and natural complex systems. This approach provides the key theoretical basis for giving full scope to the regulatory role of government departments as well as the effect of the market economy and new patterns of regional coordinated development. This approach has also effectively enabled social organizations to correctly recognize and reasonably plan for land spatial construction (Fan, 2013).

\subsection{Sustainable development and resources and environmental carrying capacity}

The concept of sustainable development was first defined by the World Commission on Environment and Development as 'meeting the needs of the present without affecting the needs of future generations' (Brundtland et al., 1987). In recent years, the 'future Earth' research plan (Fan and Jiang, 2015) as well as 2030 Global Sustainable Development Goals (SDGs) have also been proposed (UN, 2015). Although the Chinese economy has achieved long-term and high-speed growth since 1978, significant structural problems are also seen including overcapacity (Lu, 2015). This growth has also led to ecological damage (Liang et 
al., 2019a), environmental pollution (Liang et al., 2019b), and a range of other problems. To enhance sustainable development, urban agglomerations are now expected to adhere to the sustainable rising law (Fang et al., 2019). Research on resources and environmental carrying capacities have further deepened our understanding of sustainable development, an area of high value to the Chinese government (Chen et al., 2017). It is hoped that by systematically and quantitatively evaluating the capacities of resources, the environment, ecology, and other features to carry human production we can better understand the interactions between natural and human elements (Zheng et al., 2016). Affording attention to the interactive coupling effect of resources, the environment, and economic development can support sustainable development (Hao et al., 2019; Niu et al., 2019); this research area therefore provides an important basis for land spatial planning (Zhou et al., 2019).

\subsection{New urbanization}

A significant amount of attention was paid in the past to the urbanization process in order to accelerate it at the expense of quality (Lu et al., 2007). In order to mitigate this trend, it was proposed in 2007 that human development in China should be at the core of urbanization (Chen et al., 2007). The Chinese government then proposed in 2011 that urbanization should also include healthy human development, the urban-rural relationship, and resources and the environment (Chen et al., 2011). It is therefore no longer appropriate to regard urbanization acceleration as a core development policy (Chen, 2011b). The 2014 'New Urbanization Plan' for China highlighted the fact that urbanization should be human-oriented (Lu et al., 2015); healthy urbanization is therefore now an important academic idea that supports our transformation to a new growth model. At the national level, a 'healthy development plan of urbanization' has also been implemented, now finally defined as the 'new-type urbanization plan.' Indeed, to avoid the use of too many nouns, healthy urbanization has been renamed, but remains essentially the same. Connotations of new-type urbanization theory include human nature, coordination, inclusiveness, and sustainability (Chen et al., 2019). This concept is therefore significantly different from earlier models of urbanization which pursued economic and single-factor growth as well as partial benefits and were therefore unsustainable. It is also clear that new-type urbanization should make rational use of land resources (Yao et al., 2012), recognize regional differences (Zhou, 1983), attach importance to climate change, resources, and the environment (Gu et al., 2009), and even establish a global perspective (Xue et al., 2010). This new-type urbanization across China is still being initiated; long-term development and quality improvement processes will be required as well as sustained and in-depth academic research support. Urban agglomerations have become the main source of Chinese socioeconomic development; this means that the proposed ' $5+9+6$ spatial patterns for urban agglomerations' (referring to the construction of five national-level, nine regional-level, six local-level urban agglomerations) (Fang, 2015) will be of great significance for future land planning (Fang et al., 2015b).

\subsection{A multi-system in rural areas}

A regional system for urban and rural areas was proposed across China in 2008; this system elaborated on the coupling of urban and rural systems and emphasized the transformation of rural areas as well as the integration of urban and rural development (Zhang et al., 2008). 
The objective of urban-rural integration and rural revitalization is multi-system in rural areas and includes urban-rural integration, the rural complex, the village and town organism, and residential and industry coordination. The concept of rural revitalization therefore emphasizes optimization and the reconstruction of an urban-rural integration system as well as accelerating the construction of a multi-level target system comprising an urban-rural basic network, a rural development zone, a rural space field, and a rural revitalization pole. The issue of 'agriculture, rural areas, and farmers' across China is essentially a problem of sustainable development within the context of the regional rural system. Rural development therefore faces the inter-related issues of high-speed non-agricultural production factors, the rapid aging and weakening of rural residents, increasingly empty and wasted rural construction land, the serious pollution of rural soil and aqueous environments, and intense poverty. Rural areas are an important component of spatial land use as well as one key foundation for socioeconomic development (Liu, 2018).

\section{The framework of land spatial planning: A geographic perspective}

In light of the vision and goals of the 'Beautiful China' concept, it is important to discuss just how China can achieve land spatial planning to optimize the allocation of resources? A number of clear traditional advantages underpin the important role of geography in land spatial planning. The geography includes physical geography, human geography and geographic information system (including remote sensing, etc.) from the perspective of three parts, while mainly consists of spatial, regional and comprehensive thinking from the perspective of geography classical thinking. These methods are of great significance to land spatial planning. Indeed, in terms of geographical thought and related areas, this paper puts forward a clear land spatial planning framework (Figure 5) which primarily comprises (Figure 6) a natural background of land and space, socioeconomics, regional connections, a vision and path for land spatial planning, public participation and dynamic assessment, and intelligent decision-making systems in order to provide future inspiration to this policy field.

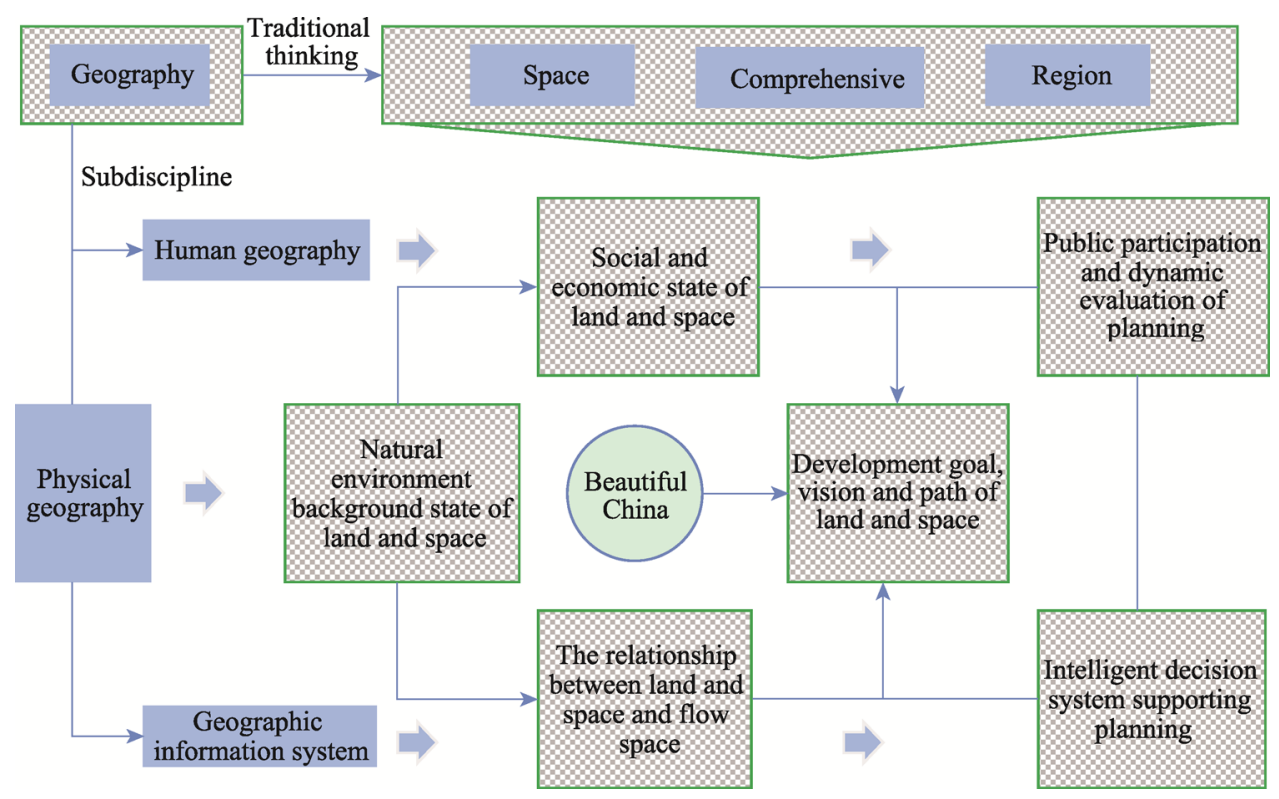

Figure 5 A geographic land spatial planning framework 


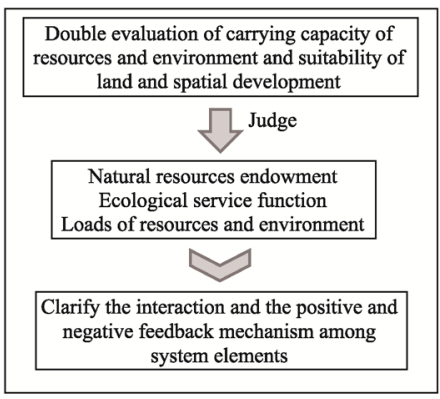

(a) Natural background

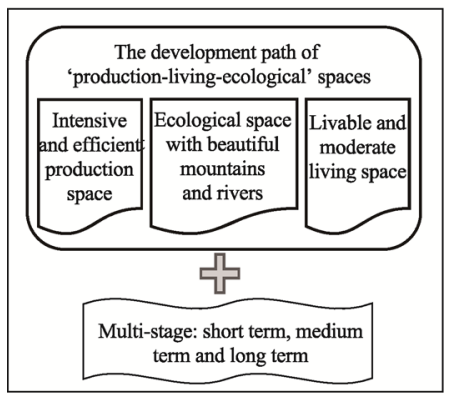

(d) Goal vision

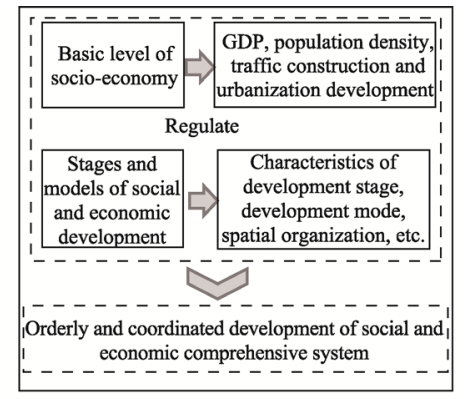

(b) Socio-economy

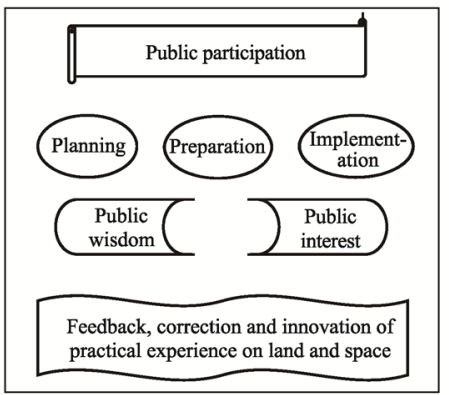

(e) Public participation

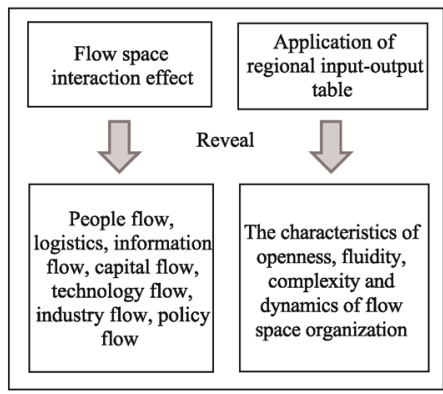

(c) Spatial connection

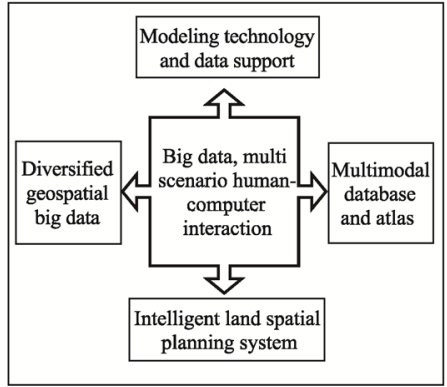

(f) Decision-making system

Figure 6 Main components of a land spatial planning framework

\subsection{The land and space natural background: Double evaluation of resource carrying capacity, environment, and the suitability of land and space development}

In this new era, the premise and foundation of spatial planning is to clarify the natural background of land and space. This means it is necessary to develop a comprehensive understanding and evaluation system for natural resource endowments, ecological service functions, the geographic environmental carrying capacity, and other multi-element background features of land and space. The carrying capacity of resources and the environment as well as resource endowments and ecological conditions means that we can clarify the limitations and suitability of land development and propose the 'double evaluation' method (i.e., the evaluation of resource and environmental carrying capacity as well as the suitability of land and space development) for land spatial planning. The 'double evaluation' method can then be used to analyze resources as well as the environment and ecology of the land and spatial system in order to perform a comprehensive evaluation encompassing human activities. This approach enables us to accelerate our basic work including delimiting ecological protection red lines as well as those for the permanent basic protection of farmland and the three control lines that mark the boundaries of urban development.

\subsection{The socioeconomic basis of land and space: The intensity of land development and a model and stage for socioeconomic development}

In addition to natural background, the socio-economy refers to human activities that must be regulated in the context of land spatial planning. Land spatial patterns are therefore a comprehensive reflection of the interaction and coupling of natural resources, the environment, and the socioeconomic system. Subsequent to Chinese reform and opening-up, the devel- 
opment of urbanization and industrialization has continued to increase alongside land and spatial development. At the same time, contradictions between socioeconomic development and resource and environmental protection have become increasingly intense (Chen, 2011a). Our current understanding of land spatial planning focuses on regional socioeconomics, the stage and mode of this development as well as the integration, optimization, and coordinated development of behavioral process. Scientific calculations as well as in-depth analysis of the intensity of land and spatial development must be based on the intensity of land, resources, and environmental carrying capacity in order to comprehensively guide the orderly development and efficient use of land and space across China.

\subsection{Land-space interactions: Flow space interactions, a cross-regional input-output table, and further applications}

In light of the rapid development of economy and society in China as well as continuous progress in transportation technology, connections between different cities and regions have become ever closer. Thus, as part of the land-space planning process, we must fully consider the impacts of flow space interactions on land space. This will enable us to break the current emphasis on scale and the past level of physical space utilization in order to create conditions for the complete flow of elements. An input-output table is therefore useful because it reveals the mechanisms of industrial connections in different regions and can also be utilized to quantitatively explore the influence of flow spatial organization on the total elements of land and space. Thus, by analyzing the characteristics of openness, liquidity, complexity, and the dynamics of pedestrian, logistics, information, and capital flow spatial organization we can improve spatial flow and the allocation efficiency of regional elements. This will also enable us to construct a coordinated, orderly, rapid, and efficient land spatial contact network (Fan, 2016).

\subsection{Vision and path of land spatial planning: The vision and development path design of land spatial planning}

In order to achieve our goal of comprehensively optimizing land space, planning in this area should rely completely on our scientific understanding of natural background, the socioeconomy, and land space regional connections. This will then enable us to propose a layout and overall development plan for production, living, and ecological space in urban and rural areas across different spatial scales. Land spatial planning must therefore be combined with the overall goal and phased goals of the 'Beautiful China' concept and, as such, will focus on the high-quality development requirements of both land and space. Proposing a short-, medium-, and long-term multi-stage developmental vision of land spatial planning at different scales and levels will mean that this process can be applied to design scientific and reasonable space development paths and create a new pattern comprising 'production-livingecological' spaces, 'intensive and efficient production space, livable and moderate living space, and beautiful ecological space.'

\subsection{Public participation and dynamic evaluation: Public participation and the evaluation, feedback and correction of planning}

As part of the process of land spatial planning, it is important to emphasize scientific ideas, 
innovation, and public participation. These feedbacks will enable us to adhere more closely to the scientific decision-making mode led by the government, guided by experts, and including public participation. It is therefore necessary to encourage the public to participate in land spatial planning and to provide evaluation services regarding effects. Thus, by widely seeking 'public wisdom' and coordinating 'public interest,' we are able to work together to create a scientific and efficient land spatial planning process. Efforts have to date been focused on establishing national, provincial, municipal, and county-level 'land spatial planning committees.' In order to gather the planning functions of each department, China must be responsible for the preparation, declaration acceptance, conflict coordination, supervision, and management of land spatial planning and to conduct ongoing dynamic supervision and evaluation of the content, progress, and effects of planning implementation. We aim to expand the channels for the public to apply for spatial planning in order to ensure that everyone can gradually become an important supervisor, promoter, and assessor of spatial planning.

\subsection{An intelligent decision-making system for land spatial planning: Big data tech- nology and intelligent spatial planning}

Big data applications were applied first in the social sciences (Floridi, 2012) and have more recently been gradually integrated into geographic research (Wu et al., 2015; Zhen and Wang, 2015). At present, big data technology provides technical and information support for the comprehensive evaluation of the socio-economy (Zhen et al., 2015b) and has thus been widely cited as part of innovative research on urban spatial intelligent planning (Chai et al., 2014; Ding et al., 2016; Long et al., 2015). The application of big data in the preparation of land spatial planning remains in an exploratory stage, however. It is nevertheless possible to combine big data with multi-element investigations and material analyses based on mining and modeling technology, including land and space development, natural resources, the ecological environment, and economic society. This enables us to integrate big data across diversified geographical spaces to establish both database and atlases. We also have the ability to develop a big data cloud computing platform that can realize multi-scenario simulations through human-computer interactions. These approaches mean that we are finally able to formulate an intelligent decision-making system of land spatial planning that includes visualization, energy analysis, human-computer interactions, and effective early warning characteristics.

\section{Discussion}

The 'Beautiful China' concept combined with land spatial planning are major developments in geographic science. Scientific and technological support for relevant strategic demands also need to be strengthened, however, and numerous aspects will require further exploration.

(1) The 'Beautiful China' concept is a new national development goal within the confines of ecological civilization. This idea therefore reflects a number of new features as well as the requirements of Chinese socialism in the new era. This concept is thus essentially different from the simple pursuit of quantity and scale that was seen in the past and mainly empha- 
sizes 'people's desire for a better life'. It is therefore important to not only coordinate the relationship between ecological protection and socioeconomic development, but also to change the past development model that was driven by scale and to explore a new one based on green development. It is also necessary to pay attention to the meso- and micro-scale of 'Beautiful China' as well as land spatial planning in order to plan the construction of high-quality community life circles that are closely related to the lives of people. A number of aspects will also require further study including the definition of connotations and extension of the 'Beautiful China' concept. It will also be important to take into account the historical context of ideological evolution, interpretation of the road map of 'Beautiful China' construction, and the practical promotion of differentiated samples in various regions.

(2) The concept of 'Beautiful China' and land spatial planning are two closely related concepts. It is therefore impossible to discuss land spatial planning without also incorporating the large-scale goals of 'Beautiful China,' and vice versa. It is necessary to combine the 'Beautiful China' concept with land spatial planning and strengthen our comprehensive understanding of their relationship.

(3) Land spatial planning cannot be separated from quantitative analysis and also cannot be subsumed into econometrics. It is therefore necessary to carry out quantitative data analyses but also to emphasize professional knowledge and experience. This will enable us to study and evaluate major problems and laws in socioeconomic development as well as in land and space. The combination of these two methods will enable us to develop more scientific land spatial planning.

(4) The land and the sea need to be fully included in planning. Thus, coordination between these two environments should be strengthened while blue land spatial planning should be highly valued. China has a long coastline and a vast sea area, so the inclusion of coastal areas should speed up the implementation of special spatial planning for marine territories and promote the construction of beautiful oceans.

(5) The current land spatial planning system used across China is mainly based on administrative regions at all levels as this aids preparation and implementation. The land spatial planning framework must be open-ended, and seek refinements as well as the scientific basis for land reform and space governance on global and larger regional spatial scales. It is therefore important to promote land spatial planning across administrative regions including unified concepts within the Yangtze River Economic Belt. The integrated development of urban agglomerations in this area are deeply connected within this river basin

(6) The construction of 'Beautiful China' and the compilation of land spatial planning are in urgent need of interdisciplinary and multi-domain integration as well as innovations in theoretical methods and practical exploration. The Chinese Academy of Sciences has taken the lead in launching a 'Class-A strategic leading science and technology project' called the 'science and technology project for the construction of Beautiful China's ecological civilization.' Our goal is to provide effective scientific and technological support for national ecological civilization as well as for the construction of 'Beautiful China.' Geographical science, especially human and economic branches of this subject, will play a key role because of inherent discipline characteristics and tradition. At the same time, however, the development of geographic science needs to face up to realistic strategic demands of land spatial planning in order to further contribute in terms of subject value, the expansion of social services, and 
the consolidation of science and technology resources.

\section{Conclusions}

(1) The concept of 'Beautiful China' and land spatial planning are closely related to one another and provide unprecedented opportunities for geographic sciences. The aim of this article was therefore to discuss this concept, specifically emphasizing the fact that 'Beautiful China' is a comprehensive idea that encompasses 'economy, politics, culture, society and ecology.' The construction of 'Beautiful China' therefore requires a differentiated evaluation index system based on different scale objectives and regional characteristics. At the same time, land spatial planning will require innovations in planning methodologies that encompass interdisciplinary integration. The 'Beautiful China' concept is an important goal in spatial planning while land spatial planning itself provides an important mechanism to realize the modernization of space governance in this context.

(2) Land spatial planning provides a clear national foundation and is also novel. Thus, in order to be successful, it is necessary to strengthen our in-depth discussions at the theoretical level with regard to regional human-land relationships, the point-axis system, major functional division, new-type urbanization, and the development of urban agglomerations.

(3) This article proposes a new framework for land spatial planning. This kind of planning should encompass at least six aspects, specifically a natural background for land and space, socioeconomics, connections among regions, a vision and path for land spatial planning, public participation and dynamic assessment, and an intelligent decision-making system that is based on big data technology.

\section{References}

Brundtland G H, Khalid M, Agnelli S et al., 1987. Our Common Future. New York: Springer.

Chai Y W, Long Y, Shen Y, 2014. Big data application in China's smart city planning. International Urban Planning, 29(6): 9-11. (in Chinese)

Chen C X, 2011a. Economical and intensive use of land and resources and the transformation of resource utilization methods promote the transformation of economic and social development. Land and Resources Information, (10): 8-13. (in Chinese)

Chen M X, 2011b. Accelerating urbanization should not become the national strategic choice during "the 12th Five-Year Plan” period: A discussion with Professor CHEN Yu-he. China Soft Science, (3): 1-9. (in Chinese)

Chen M X, 2015. Research progress and scientific issues in the field of urbanization. Geographical Research, 34(4): 614-630. (in Chinese)

Chen M X, 2017. Understanding and analysis of 2017 government work report from view of human and economic geography. Journal of the Chinese Academy of Sciences, 32(4): 426-434. (in Chinese)

Chen M X, Gong Y H, 2016a. Research progress and influence of series of consulting reports of urbanization. Geographical Research, 35(11): 2015-2024. (in Chinese)

Chen M X, Long H L, Wang C J et al., 2016b. The review and prospects of China's human and economic geography: The overview of "High Level Forum of the Development of Chinese Human and Economic Geography under the Background of Change". Acta Geographica Sinica, 71(8): 1456-1471. (in Chinese)

Chen M X, Ye C, 2011. Healthy urbanization: A new conception and policy explanation. Human Geography, 26(2): 56-61. (in Chinese)

Chen M X, Ye C, Fu C W, 2007. Urbanization level in China: A retrospect and consideration. Urban Planning 
Forum, (6): 54-59. (in Chinese)

Chen M X, Ye C, Lu D D et al., 2019. Cognition and construction of the theoretical connotation of new urbanization with Chinese characteristics. Journal of Geographical Sciences, 29(10): 1681-1698.

Ding L, Niu X, Song X D, 2016. Measuring the employment center system in Shanghai central city: A study using mobile phone signaling data. Acta Geographica Sinica, 71(3): 484-499. (in Chinese)

Fan J, 2004. Comprehensiveness of geography and integrated research on regional development. Acta Geographica Sinica, 59(Suppl.): 33-40. (in Chinese)

Fan J, 2007. The scientific foundation of major function oriented zoning in China. Acta Geographica Sinica, 62(4): 339-350. (in Chinese)

Fan J, 2013. The strategy of major function oriented zoning and the optimization of territorial development patterns. Journal of Chinese Academy of Sciences, 28(2): 193-206. (in Chinese)

Fan J, 2016. Theoretical innovation in optimization of protection and development of China's territorial space and coping strategy of 13th Five-year Plan. Proceedings of the Chinese Academy of Sciences, 31(1): 1-12. (in Chinese)

Fan J, 2017. Perspective of China's spatial governance system after 19th CPC National Congress. Journal of the Chinese Academy of Sciences, 32(4): 396-404. (in Chinese)

Fan J, Guo R, Chen D, 2016. The implications of five new development concepts on the main orientation of spatial planning in the 13th Five-Year Plan period. Urban Planning Forum, (2): 10-17. (in Chinese)

Fan J, Jiang Z L, 2015. Trend of human-economic geography in relation to the future earth initiative for systemic solutions of regional sustainable development. Progress in Geography, 34(1): 1-9. (in Chinese)

Fan J, Wang Y F, Chen D et al., 2015. Analysis on the spatial development structure of the Yangtze River Economic Belt. Progress in Geography, 34(11): 1336-1344. (in Chinese)

Fang C L, 2015. Important progress and future development direction of China's urban agglomeration research. Journal of Geographical Sciences, 25(8): 1003-1024.

Fang C L, Liang L W, Wang Z B, 2019. Quantitative simulation and verification of upgrade law of sustainable development in Beijing-Tianjin-Hebei urban agglomeration. Science China Earth Sciences, 62(12): 2031 2049.

Fang C L, Mao Q Z, Ni P F, 2015a. Discussion on the scientific selection and development of China's urban agglomerations. Acta Geographica Sinica, 70(4): 515-527. (in Chinese)

Fang C L, Wang Z B, Liu H M, 2019. Exploration on the theoretical basis and evaluation plan of Beautiful China construction. Acta Geographica Sinica, 74(4): 619-632. (in Chinese)

Fang C L, Wang Z B, Xu G, 2016. Spatial distribution of $\mathrm{PM}_{2.5}$ in Chinese urban agglomerations. Journal of Geographical Sciences, 26(11): 1519-1532.

Fang C L, Zhou C H, Wang Z B, 2015b. Sustainable development strategy and priorities of spatially differentiated development of urban agglomerations along the Yangtze River Economic Belt. Progress in Geography, 34(11): 1398-1408. (in Chinese)

Floridi L, 2012. Big data and their epistemological challenge. Philosophy and Technology, 25(4): $435-437$.

Fu C Y, 2019. Focusing on reform and innovation to build a beautiful new Fujian: Exploration and practice of promoting the legalization of ecological civilization construction in Fujian province. China Environment Supervision, (1): 32-36. (in Chinese)

Fu H L, Cao Y F, Yu M J, 2018. Empirical research on dynamic mechanism of ecological civilization construction of Zhejiang's beautiful countryside. Ecological Economy, 34(5): 218-223. (in Chinese)

Gao F, Zhao X Y, Song X Y et al., 2019b. Connotation and evaluation index system of Beautiful China for SDGs. Advances in Earth Science, 34(3): 75-85. (in Chinese)

Gao Q, Luo H S, Wang Z B et al., 2019a. Research progress and prospect of Beautiful China. Progress in Geography, 38(7): 1021-1033. (in Chinese)

Gu C L, Tan Z B, Liu W et al., 2009. A study on climate change, carbon emissions and low-carbon city planning. Urban Planning Forum, (3): 38-45. (in Chinese) 
Hao Q, Deng L, Feng Z M, 2019. Carrying capacity reconsidered in spatial planning: Concepts, methods and applications. Journal of Natural Resources, 34(10): 2073-2086. (in Chinese)

Healey P, 1998. Collaborative planning shaping places in fragmented societies. Journal of Rural Studies, 14(2): 269-271.

Hu G Z, Li J, Hua Q H, 2018. The theoretical guidance of Xi Jinping's Two Mountains on the Jiangxi model of Beautiful China. Theory Research, (5): 18-19. (in Chinese)

Huang X J, 2018. Beautiful China and the land space use control. Journal of China University of Geosciences (Social Sciences Edition), 18(6): 1-7. (in Chinese)

Liang L W, Wang Z B, Fang C L et al., 2019a. Spatiotemporal differentiation and coordinated development pattern of urbanization and the ecological environment of the Beijing-Tianjin-Hebei urban agglomeration. Acta Ecologica Sinica, 39(4): 1212-1225. (in Chinese)

Liang L W, Wang Z B, Li J X, 2019b. The effect of urbanization on environmental pollution in rapidly developing urban agglomerations. Journal of Cleaner Production, 237: 117649.

Li G P, Xu Y, 2001. A phase diagram analysis of the transition in the regional economic structure. Chinese Social Sciences, (2): 15-26. (in Chinese)

Li Z, 2013. Building a Beautiful China to achieve sustainable development. Economic Research Journal, 48(2): 17-19. (in Chinese)

Lin J, Wu Y X, Wu J Y et al., 2018. Construction of the spatial planning system: with discussion of the relationship between spatial palnning, regulation, and natural resources supervision. Urban Planning, 42(5): 9-17. (in Chinese)

Liu H, Fan J, Li Y, 2013. “America 2050” strategic spatial planning and its inspiration to China. Geographical Research, 32(1): 90-98. (in Chinese)

Liu H, Fan J, Wang C S, 2008. Progress in the study of European spatial planning and the inspiration to China. Geographical Research, 27(6): 1381-1389. (in Chinese)

Liu Y S, 2018. Research on the urban-rural integration and rural revitalization in the new era in China. Acta Geographica Sinica, 73(4): 637-650. (in Chinese)

Liu Y S, Wang J Y, 2016. Theoretical analysis and technical methods of "multiple planning integration" in the rural to urban transition period in China. Progress in Geography, 35(5): 529-536. (in Chinese)

Long Y, Han H, Tu Y et al., 2015. Evaluating the effectiveness of urban growth boundaries using human mobility and activity records. Cities, 46(6): 76-84.

Lu D D, 1987. The macro strategy of regional development in China. Acta Geographica Sinica, 42(2): 97-105. (in Chinese)

Lu D D, 1988. Location Theory and Regional Research Methods. Beijing: Science Press. (in Chinese)

Lu D D, 2015. Moderate-speed growth: sustainable development of China's economy. Scientia Geographica Sinica, 35(10): 1207-1219. (in Chinese)

Lu D D, Chen M X, 2015. Several viewpoints on the background of compiling the "National New Urbanization Planning (2014-2020)". Acta Geographica Sinica, 70(2): 179-185. (in Chinese)

Lu D D, Yao S M, Li G P et al., 2007. Comprehensive analysis of the urbanization process based on China's conditions. Economic Geography, 27(6): 883-887. (in Chinese)

Lu Y Q, 2002. The scientific connotation of pole-axis theory. Scientia Geographica Sinica, 22(2): 136-143. (in Chinese)

Meng P, Feng G J, Wu D F, 2015. Causes of the multiple-planning conflict and principle of multiple-planning integration: reviews of the workshop "land use conflicts and multiple planning integration". China Geosciences, 29(8): 3-9. (in Chinese)

Niu F Q, Feng Z M, Liu H, 2019. Evaluation of resources environmental carrying capacity and its application in industrial restructuring in Tibet, China. Acta Geographica Sinica, 74(8): 1563-1575. (in Chinese)

Shi P F, Li X M, Xiong Y B, 2018. Coupling measurement and prospect forecast of regional "Beautiful China" construction and tourism industry development: A case study of 11 provinces along the Yangtze River Eco- 
nomic Belt. China Soft Science, (2): 86-102. (in Chinese)

United Nations (UN), 2015. Transforming Our World: The 2030 Agenda for Sustainable Development. New York: United Nations.

Wan J R, Pan J H, Lv Z M et al., 2013. Commentaries: Ecological civilization and "Beautiful China". Social Sciences in China, 5(4): 204-205. (in Chinese)

Wang J N, Jiang H Q, Zhang H Y et al., 2012. Strategic framework design for ecological civilization construction in beautiful China. Environmental Protection, (23): 14-18. (in Chinese)

Wang Z B, Liang L W, Fang C L et al., 2018. Study of the evolution and factors influencing ecological security of the Beijing-Tianjin-Hebei urban agglomeration. Acta Ecologica Sinica, 38(12): 4132-4144. (in Chinese)

Wang Z B, Liang L W, Sun Z et al., 2019. Spatiotemporal differentiation and the factors influencing urbanization and ecological environment synergistic effects within the Beijing-Tianjin-Hebei urban agglomeration. Journal of Environmental Management, 243: 227-239.

Wu C J, 2008. Human-earth Relationship and Economic Layout. Beijing: Academy Press. (in Chinese)

Wu Z F, Chai Y W, Dang A et al., 2015. Geography interact with big data: Dialogue and reflection. Geographical Research, 34(12): 2207-2221. (in Chinese)

Xinhua News Agency (XNA), 2018. Xi Jinping attended the National Ecological Environmental Protection Conference and delivered an important speech. Website of the Central People's Government of the People's Republic of China, 05-19. (in Chinese)

Xue D S, Huang G Z, Weng X L et al., 2010. Urban globalization process of China's cities since the early $1980 \mathrm{~s}$. Acta Geographica Sinica, 65(10): 1155-1162. (in Chinese)

Yao S M, Lu D D, Chen Z G et al., 2012. Serious thinking on urbanization in line with China's national conditions. Economic Geography, 32(5): 1-6. (in Chinese)

Yu L L, Cai Y Y, 2016. Effects of national spatial planning to economic growth in key development areas: Evidence from the planning of Wuhan urban agglomeration. China Population, Resources and Environment, 26(9): 101-109. (in Chinese)

Zhang F G, Liu Y S, 2008. Dynamic mechanism and models of regional rural development in China. Acta Geographica Sinica, 63(2): 115-122. (in Chinese)

Zhang J H, 2018. Implement the guiding principles of the 19th National Congress of the CPC to forge ahead into the Beautiful Yunnan. Journal of Southwest Forestry University (Social Sciences), 2(1): 1-10. (in Chinese)

Zhang L, Lu Y Q, 2010. Studies on spatial analysis method of the "pole \& axis system": A case study of the Yangtze River Delta. Acta Geographica Sinica, 65(12): 1534-1547. (in Chinese)

Zhang Y J, Fang C L, 2016. A Review on spatial planning coordination and China's "coordinated planning". Journal of Urban Planning, (2): 78-87. (in Chinese)

Zhang Y Y, Chen M J, 2016. Spatial systematic cognition and ideas on spatial planning system reform. China Land Science, 30(2): 11-21. (in Chinese)

Zhen F, Wang B, 2015. Rethinking human geography in the age of big data. Geographical Research, 34(5): 803-811. (in Chinese)

Zhen F, Wang B, Qin X et al., 2015. Innovation of Urban Research and Planning Methods Based on Big Data. Beijing: China Construction Industry Press, 98-113. (in Chinese)

Zheng D, Wu S H, Yin Y H et al., 2016. Frontiers in terrestrial system research in China under global change. Acta Geographica Sinica, 71(9): 1475-1483. (in Chinese)

Zhou K, Fan J, Sheng K R, 2019. Research on methods and approaches of spatial governance. Geographical Research, 38(10): 2527-2540. (in Chinese)

Zhou Y X, 1983. Regional differences of urbanization in China. Urban Planning, (2): 17-21. (in Chinese) 